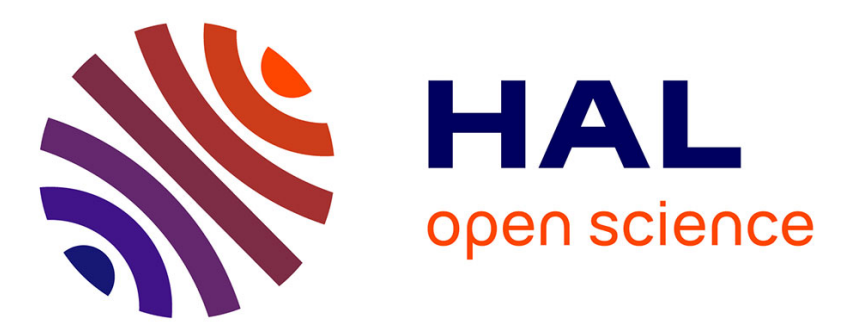

\title{
Calculation of combined diffusion coefficients from the simplified theory of transport properties
}

Vincent Rat, Pascal André, Jacques Aubreton, Marie-Françoise Elchinger, Pierre Fauchais, André Lefort

\section{- To cite this version:}

Vincent Rat, Pascal André, Jacques Aubreton, Marie-Françoise Elchinger, Pierre Fauchais, et al.. Calculation of combined diffusion coefficients from the simplified theory of transport properties. Sixth European Conference on Thermal Plasma Processes Strasbourg, France May 30 - June 3, 2001, 2001, France. pp.403-410. hal-00019952

\section{HAL Id: hal-00019952 https://hal.science/hal-00019952}

Submitted on 2 Mar 2006

HAL is a multi-disciplinary open access archive for the deposit and dissemination of scientific research documents, whether they are published or not. The documents may come from teaching and research institutions in France or abroad, or from public or private research centers.
L'archive ouverte pluridisciplinaire HAL, est destinée au dépôt et à la diffusion de documents scientifiques de niveau recherche, publiés ou non, émanant des établissements d'enseignement et de recherche français ou étrangers, des laboratoires publics ou privés. 


\title{
CALCULATION OF COMBINED DIFFUSION COEFFICIENTS FROM THE SIMPLIFIED THEORY OF TRANSPORT PROPERTIES
}

\author{
V. Rat ${ }^{1}$, P. André ${ }^{2}$, J. Aubreton ${ }^{1}$, M.F. Elchinger ${ }^{1}$, P. Fauchais ${ }^{1}$, A. Lefort ${ }^{2}$ \\ ' SPCTS University of Limoges, $123 \mathrm{av}$. A. Thomas, 87060 Limoges cedex, France \\ ${ }^{2}$ LAEPT Blaise Pascal University, 24 av. des Landais, 63177 Aubière cedex, France
}

\begin{abstract}
The aim of this study is to check if it is possible to use the combined diffusion coefficients introduced by Murphy at equilibrium in a two-temperature model (electron temperature $T_{e}$ different from that of heavy species $T_{h}$ ) such as that defined by Devoto or Bonnefoi for transport properties. Murphy's coefficients describe the diffusive mixing of two non reactive ionized gases while the Devoto's or Bonnefoi's simplified theories allow the calculation of transport coefficients (except diffusion) out of thermal equilibrium. It has to be noticed that in the latter case when $T_{e}$ tends towards $T_{h}$, the results are those obtained with an equilibrium calculation. The two-temperature (2-T) theory of transport properties was established by separating electrons and other species because of their mass difference. First, the exact combined diffusion coefficients of Murphy are calculated for an $\mathrm{Ar}-\mathrm{N}_{2}(50 \mathrm{wt} \%)$ mixture at atmospheric pressure. Then, expressions of combined diffusion coefficients are obtained using the simplified theory of Bonnefoi. The results of the calculation of combined diffusion coefficients from the simplified theory of transport properties, assuming equilibrium is achieved $\left(\mathrm{T}_{\mathrm{e}}=\mathrm{T}_{\mathrm{h}}\right)$, is compared with those of Murphy at equilibrium. It is shown that large discrepancies occur when ionization is important. These results prove that the simplified 2-T theory cannot be used for the treatment of diffusion. Thus, a new theory of transport coefficients has to be developed taking into account the coupling of electrons and heavy species and work is in progress.
\end{abstract}

Key words: Combined diffusion coefficients, thermal equilibrium

\section{1-Introduction}

The calculation of transport coefficients has been widely studied for pure gases or binary mixtures (see for example [1-5]). Ordinary and thermal diffusion coefficients, viscosity, electrical and thermal conductivities are derived by solving the Boltzmann's equation thanks to the Chapman-Enskog's method. The transport properties theory has been completed when 
Murphy [6] has introduced combined diffusion coefficients describing the whole diffusive mixing of two non reactive ionized gases at thermal equilibrium, mixing due to concentration, pressure, temperature gradients and an external electric field.

The approach of Murphy consists in describing the diffusion of two gases at high temperature, each one containing between 3 and 10 species, as a binary mixture. So, the diffusion coefficients of each species are replaced by three overall combined diffusion coefficients, $\overline{\mathrm{D}_{\mathrm{AB}}^{\mathrm{x}}}, \overline{\mathrm{D}_{\mathrm{AB}}^{\mathrm{T}}}, \overline{\mathrm{D}_{\mathrm{AB}}^{\mathrm{P}}}$ being respectively the combined ordinary, thermal and pressure diffusion coefficients of Murphy. These coefficients have to satisfy the symmetry conditions $\overline{\mathrm{D}_{\mathrm{AB}}^{\mathrm{x}}}=\overline{\mathrm{D}_{\mathrm{BA}}^{\mathrm{x}}}, \overline{\mathrm{D}_{\mathrm{AB}}^{\mathrm{T}}}=-\overline{\mathrm{D}_{\mathrm{BA}}^{\mathrm{T}}}$ and $\overline{\mathrm{D}_{\mathrm{AB}}^{\mathrm{P}}}=\overline{-\mathrm{D}_{\mathrm{BA}}^{\mathrm{P}}}$.

Under certain experimental conditions in ionized gases, the electron kinetic temperature can be different from that of other species. The fraction of kinetic energy exchanged during an elastic collision between an electron and a heavy species is so weak that a two-temperature equilibrium state can be defined so that the plasma composition and its thermodynamic properties can be obtained [7,8,9,10]. Devoto [11,12] and then Bonnefoi [13,14] developed the calculation of transport coefficients in a two-temperature plasma. Because of the small mass of electrons compared to that of heavy species, they proposed to neglect the coupling between electrons and heavy species and the mass flux of electrons.

Since it is aimed at calculating the combined diffusion coefficients in a two-temperature plasma, first, the simplified formulas of Bonnefoi have been applied at thermal equilibrium in order to obtain results similar to those of Murphy. Then, the simplified formulas written for a two-temperature plasma could be used to calculate the combined diffusion coefficients.

In the second section, the combined diffusion coefficients [6] are calculated for an Ar-N2 mixture and our results compared to those of Murphy. In the third section, the simplified formulas of Bonnefoi at thermal equilibrium are adapted to the concept of combined diffusion coefficients, that is the ambipolar diffusion coefficients are established from the simplified expression of species fluxes. In section four, these new combined diffusion coefficients are calculated and compared to the complete coefficients of Murphy. The discrepancies observed are discussed in the last section.

\section{2- Calculation of combined diffusion coefficients for an $\mathrm{Ar}-\mathrm{N}_{2}$ mixture}

The composition of the Ar- $\mathrm{N}_{2}$ mixture is needed to calculate the combined diffusion coefficients and is obtained by minimising the Gibbs free energy at atmospheric pressure. The 
calculation was performed for an $\mathrm{Ar}-\mathrm{N}_{2}(50 \mathrm{wt} \%)$ mixture. Seven species have been taken into account: electrons, $\mathrm{Ar}, \mathrm{Ar}^{+}, \mathrm{N}_{2}, \mathrm{~N}, \mathrm{~N}^{+}$and $\mathrm{N}_{2}{ }^{+}$. The combined diffusion coefficients are calculated using Eqs. (20) and (22) of reference [6]. The combined pressure diffusion coefficient will not be discussed because the contribution of pressure gradient to diffusion is quite small compared to concentration gradient [6].

The obtained results are consistent with those of Murphy and show that the combined ordinary diffusion coefficient increases with temperature until ionization is significant (more than $6 \%$ of ionization degree) at about $11000 \mathrm{~K}$ and decreases because of the Coulombic interactions between charged species.

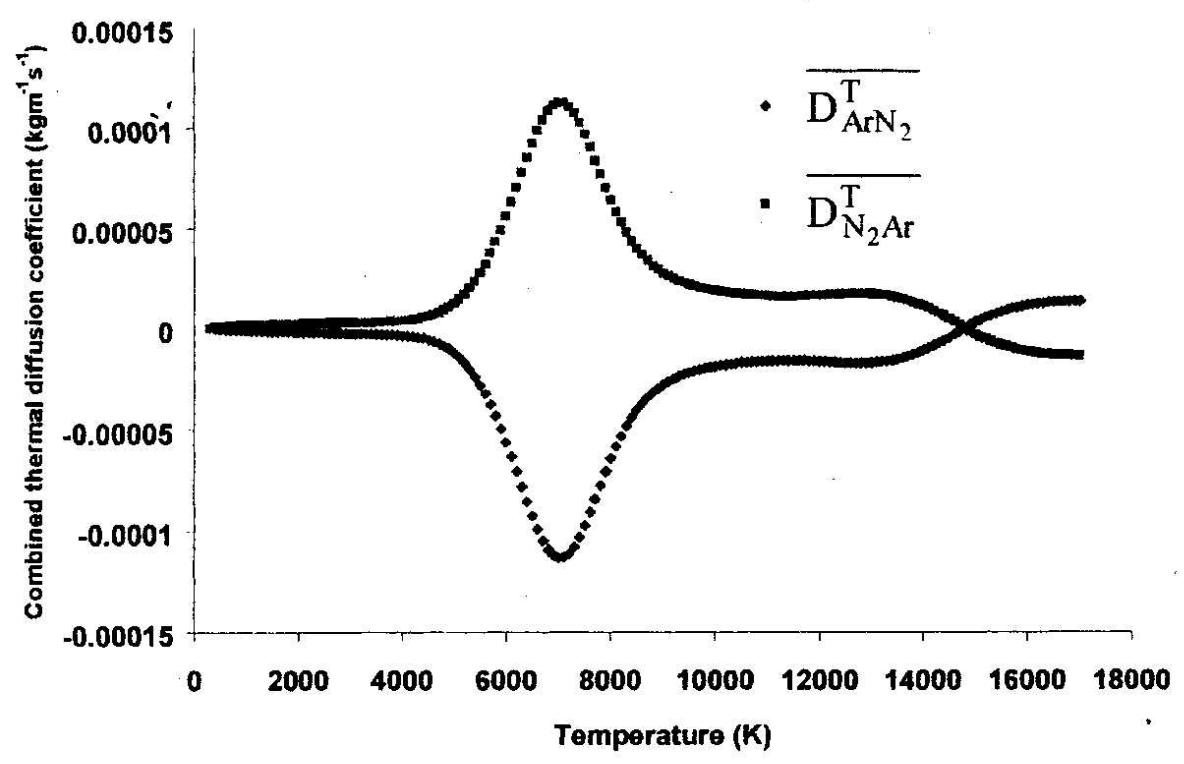

Figure 1 :Temperature dependence of combined thermal diffusion coefficients of an $\mathrm{Ar}-\mathrm{N}_{2}$ plasma at atmospheric pressure with a nitrogen weight of $50 \%$

Figure 1 shows that the relationship $\overline{\mathrm{D}_{\mathrm{ArN}}^{\mathrm{T}}}=-\overline{\mathrm{D}_{\mathrm{N}_{2} \mathrm{Ar}}^{\mathrm{T}}}$, resulting from the conservation of mass fluxes, is fully checked. The combined thermal diffusion coefficient reaches an extremum at about $7000 \mathrm{~K}$ close to the maximum of $\mathrm{N}_{2}$ dissociation.

\section{3- Ambipolar diffusion coefficients from simplified expressions of diffusion fluxes}

The ambipolar diffusion coefficients are derived from the Bonnefoi's simplified expressions of diffusion fluxes in order to calculate the combined diffusion coefficients [15].

$$
D_{i j}^{a}=D_{i j}+\frac{\alpha_{i} Z_{j}}{n_{1} m_{j} \beta}+\frac{\alpha_{i} n}{n_{1} D_{11} \beta \rho} \sum_{\ell=2}^{N} Z_{\ell} D_{\ell j}
$$




$$
D_{i}^{T a}=D_{i}^{T}+\frac{\alpha_{i} m_{i} n}{n_{1} D_{11} \beta \rho} \sum_{\ell=1}^{N} \frac{Z_{\ell} D_{\ell}^{T}}{m_{\ell}}
$$

In this expression

$$
\alpha_{i}=\sum_{j=2}^{N} n_{j} m_{j} Z_{j} D_{i j} \quad \text { (3) } \quad \beta=1-\frac{n}{\rho n_{1} D_{11}} \sum_{i=2}^{N} \sum_{j=2}^{N} Z_{i} Z_{j} n_{j} m_{j} D_{i j}
$$

$\mathrm{N}, \mathrm{n}_{\mathrm{i}}$ and $\mathrm{n}$ are the total number of species in the mixture, the number density of respectively the species $i$ and the gas mixture. The index 1 represents the electron. $D_{11}$ and $D_{1}^{T}$ are respectively the ordinary and thermal diffusion coefficients of electrons. $Z_{j}$ is the charge number of the species $j$. $\rho$ is the mass density of the gas mixture. $D_{i j}$ and $D_{i}^{T}$ are given in reference [13]. $\mathrm{D}_{\mathrm{ij}}^{\mathrm{a}}$ and $\mathrm{D}_{\mathrm{i}}^{\mathrm{Ta}}$ are the ambipolar ordinary and thermal diffusion coefficients due to concentration and temperature gradients. They are needed to calculate the combined diffusion coefficients given by

$$
\begin{aligned}
& \overline{\mathrm{D}_{\mathrm{AB}}^{\mathrm{x}}}=\frac{1}{\overline{\mathrm{m}_{B}}} \sum_{\mathrm{i}=2}^{\mathrm{p}} \mathrm{s}_{\mathrm{i}} \sum_{j=2}^{\mathrm{N}} \mathrm{m}_{\mathrm{j}} \mathrm{D}_{\mathrm{ij}}^{\mathrm{a}}\left(\frac{\partial \mathrm{x}_{\mathrm{j}}}{\partial \mathrm{x}_{\mathrm{B}}}\right) \\
& \overline{\mathrm{D}_{\mathrm{AB}}^{\mathrm{T}}}=\overline{\mathrm{m}_{\mathrm{A}}} \sum_{\mathrm{i}=2}^{\mathrm{p}} \mathrm{s}_{\mathrm{i}}\left(\frac{\mathrm{D}_{\mathrm{i}}^{\mathrm{Ta}}}{\mathrm{m}_{\mathrm{i}}}-\frac{\mathrm{n}^{2}}{\rho} \sum_{\mathrm{j}=2}^{\mathrm{N}} \mathrm{m}_{\mathrm{j}} \mathrm{D}_{\mathrm{ij}}^{\mathrm{a}} \mathrm{T}\left(\frac{\partial \mathrm{x}_{\mathrm{j}}}{\partial \mathrm{T}}\right)\right)
\end{aligned}
$$

where $s_{j}$ are stoichoimetric coefficients and $\overline{\mathrm{m}_{\mathrm{A}}}$ and $\overline{\mathrm{m}_{\mathrm{B}}}$ the average masses of the species in gases $A$ and $B$ defined by Murphy [6]. The index of species belonging to gas $A$ varies from 2 to $p$ whereas that of species in gas $B$ varies from $p+1$ to $N$. The expressions of $\overline{D_{B A}^{X}}$ and $\overline{D_{B A}^{T}}$ are similar. In that case, the sum over $i$ runs from $p+1$ until $N$ and a negative sign appears in front of $\overline{\mathrm{D}_{\mathrm{BA}}^{\mathrm{X}}}$.

\section{4-Application of combined diffusion coefficients derived from simplified expressions for an Ar- $\mathrm{N}_{2}$ mixture and comparison with the complete formulas of Murphy}

The combined diffusion coefficients are calculated for the $\mathrm{Ar}-\mathrm{N}_{2}$ mixture and compared to those calculated in section 2. First, the combined ordinary diffusion coefficients $\overline{\mathrm{D}_{\mathrm{ArN}_{2}}^{\mathrm{x}}}$ and $\overline{\mathrm{D}_{\mathrm{N}_{2} \mathrm{Ar}}^{\mathrm{x}}}$ are not identical once a significant ionization (more than $6 \%$ of ionization degree) occurs and, at $17000 \mathrm{~K}$ when the ionization of $\mathrm{Ar}$ is completed, the relative error 
between these two coefficients reaches $30 \%$. The comparison between the exact $\overline{\mathrm{D}_{\mathrm{ArN}_{2}}^{\mathrm{x}}}$ of Murphy and that of obtained by using the simplified expressions of Bonnefoi shows similar results. Below $8000 \mathrm{~K}$, Eq.(5) is a quite good approximation of $\overline{\mathrm{D}_{\mathrm{ArN}}^{\mathrm{x}}}$ of Murphy, but at about $17000 \mathrm{~K}$, the discrepancy is 7,5\%. The difference between $\overline{\mathrm{D}_{\mathrm{N}_{2} \mathrm{Ar}}^{\mathrm{x}}}$ and that calculated at equilibrium in section 2 is more important at $17000 \mathrm{~K}$ reaching almost $21 \%$.

Figure 2 shows the temperature dependence of thermal diffusion coefficients $\overline{\mathrm{D}_{\mathrm{ArN}_{2}}^{\mathrm{T}}}$ and $\overline{\mathrm{D}_{\mathrm{N}_{2} \Lambda \mathrm{r}}^{\mathrm{T}}}$ calculated using the simplified expressions of fluxes.

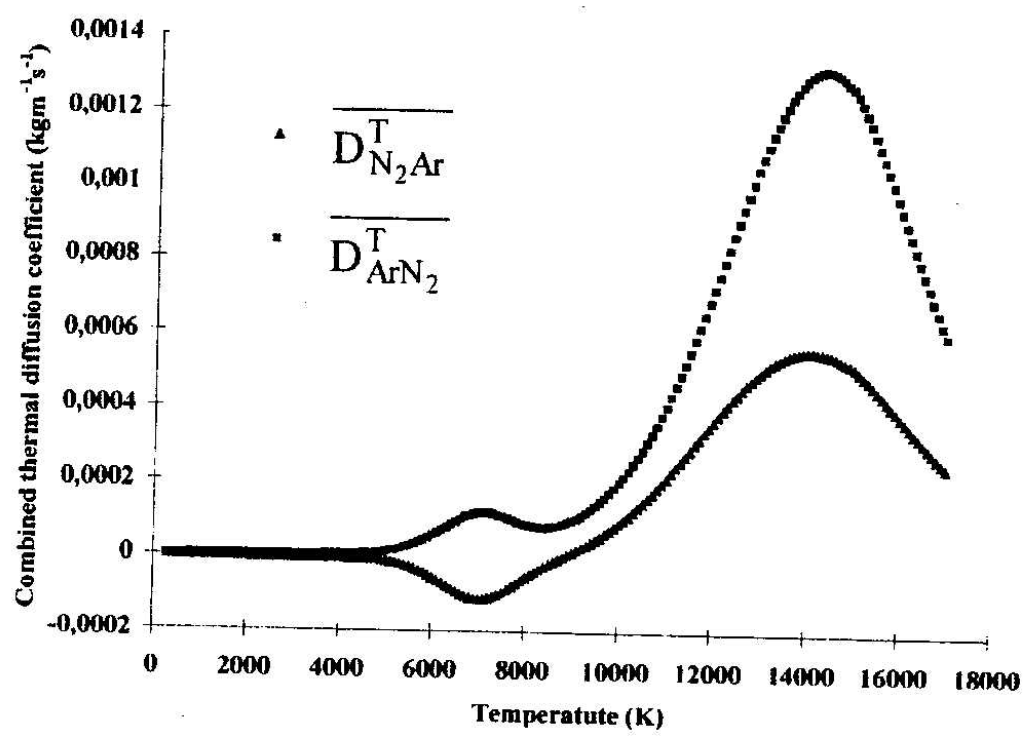

Figure 2 :Temperature dependence of $\overline{\mathrm{D}_{\mathrm{ArN}_{2}}^{T}}$ and $\overline{\mathrm{D}_{\mathrm{N}_{2} \mathrm{Ar}}^{T}}$ obtained from Bonnefoi's simplified expressions for an $\mathrm{Ar}-\mathrm{N}_{2}(50 \mathrm{wt} \%)$ plasma at atmospheric pressure.

Below $8000 \mathrm{~K}$, there is a good agreement with the Murphy's coefficients. However, once ionization is important, the behavior of combined thermal diffusion coefficients is completely inconsistent. In fact, although the formulation of combined diffusion coefficients given in section 3 seems to be correct up to about $8000 \mathrm{~K}$, ionization is not taken into account by equations (5) and (6). As a result, the simplified expressions introduced by Devoto or Bonnefoi cannot be used to account for the diffusive mixing of gas mixtures.

\section{5-Discussion}

Before ionization is really started (less than $6 \%$ of ionization degree), the good agreement of the results of equations (5) and (6) with those obtained with Murphy's combined 
diffusion coefficients shows that the way the derivation of ambipolar diffusion coefficients has been carried out [15] is correct. Firstly, it has been checked using (1) and (2) that the sum of charged species currents vanishes whatever may be the temperature. Secondly, Section 4 shows that the sum of mass fluxes also vanishes when the number density of electrons is quite small because their influence on calculation of diffusion coefficients is negligible at low temperature. Thus, it is the simplified expressions of mass fluxes $[13,14]$ which are questionable when the number density of electrons is important. The discrepancies observed in section 4 mean that the sum of mass fluxes of species does not vanish. In the standard theory of calculation of transport coefficients at equilibrium [1], this condition is fulfilled by an equation constraining the system obtained from the linearization of the Boltzmann's equation thanks to the Sonine polynomials. It thus allows the calculation of ordinary and thermal diffusion coefficients through:

$$
\sum_{i=1}^{N} n_{i} \sqrt{m_{i}} t_{i 0}^{(h, k)}=0
$$

where $\mathrm{N}$ is the total number of species in the mixture, $\mathrm{h}$ and $\mathrm{k}$ being indexes varying from 1 to N. $t_{i 0}^{(h, k)}$ is related to other coefficients called $c_{i 0}^{(h, k)}$ or $a_{i 0}$ on which the ordinary and thermal diffusion coefficients depends. The index 0 in $t_{i 0}^{(h, k)}$ corresponds to the first term in the expansion of Sonine polynomials. When Bonnefoi separated electrons and heavy particles in order to establish the simplified expressions of species fluxes, he neglected the mass flux of electrons. So, in this assumption, the sum of equation (7) starts from 2 up to N. so that the mass flux of electrons is not constrained anymore which may explain the discrepancies noted in the previous section. Thus, the combined diffusion coefficients could be applied out of thermal equilibrium only if transport coefficients are derived without the assumptions of Bonnefoi. This implies that the Chapman-Enskog method has to be adapted to solve the Boltzmann's equation out of thermal equilibrium, in agreement with the H-theorem. At thermal equilibrium, the latter allows the introduction of the Maxwellian distribution function.

In the two-temperature approach, it was assumed that the electron temperature $T_{e}$ is different from that of the heavy species $T_{h}$ and an equilibrium state may exist. However, it has to be underlined that a two-temperature system is a non uniform system even though the equilibrium state exists owing to the small fraction of energy exchanged during a collision between electrons and heavy species. As a result, it is expected to create coupled effects of mass and 
energy fluxes. Besides, it is admitted that thermal disequilibrium originates in the presence of an external electric field. The external influence of the latter is not negligible since the thermal energy of electrons, compared to that of thermal equilibrium, is considerably modified. Thus, from this point of view, the $\mathrm{H}$-theorem of a two temperature plasma cannot be applied in term of isolated systems. Consequently, the $\mathrm{H}$ function [1] cannot indicate the way of evolution of the two-temperature system, contrary to the thermal equilibrium, but only that its entropy is stable in time [16]. The transport coefficients of a two temperature plasma can be derived by assuming that the distribution function of species is a Maxwellian distribution function perturbed by a first-order perturbation function depending on $T_{e}$ and $T_{h}$ which enables the coupling between electrons and heavy species to be taken into account. This dependence implies a generalization of the definition of the bracket integrals given by Chapman et al. [2] to the multitemperature plasma allowing the transport coefficients to be expressed in terms of linear combinations of collision integrals.

\section{6- Conclusion}

As a conclusion, it has been shown the combined diffusion coefficient introduced by Murphy cannot be calculated using the simplified expressions given first, at thermal equilibrium, by Devoto and modified, out of thermal equilibrium, by Bonnefoi. The assumptions made to separate electrons and heavy species do not hold for the treatment of diffusion. The application out of thermal equilibrium of the simplified expressions which consists only in giving the temperature $T_{e}$ to the electrons one and $T_{h}$ to the heavy species cannot be used. Thus, a complete theory for the calculation of transport coefficients out of thermal equilibrium has to be developed in order to take into account the coupling between electrons and heavy species and will be presented in a next paper.

\section{References}

[1] Hirschfelder J.O., Curtis C.F., Bird R.B., Molecular Theory of Gases and Liquids, 2nd ed., Wiley, New York, 1964

[2] Chapman S., Cowling T.G., The Mathematical Theory of Non-Uniform Gases, 3nd ed., Cambridge University Press, Cambridge, England, 1970

[3] Murphy A.B, Arundel, C.J., Transport Coefficients of Argon, Nitrogen, Oxygen, ArgonNitrogen, and Argon-Oxygen Plasmas, Plasma Chemistry and Plasma Processing, Vol 14, no4,1994, pp451-490 
[4] Murphy A.B., Transport coefficients of Air, Argon-Air, Nitrogen-Air, and Oxygen-Air Plasmas, Plasma Chemistry and Plasma Processing, Vol 15, no2, 1995, pp279-307

[5] Capitelli M, Celiberto R., Gorse C., Transport Properties of High Temperature Air Components: A Review, Plasma Chemistry and Plasma Processing, Vol 16, no1, 1996, pp267302

[6] Murphy A.B., Diffusion in Equilibrium Mixtures of Ionized Gases, Physical Review E, vol 48, no5, 1993, pp3594-3603 and Erratum, Physical Review E, vol 50, pp50-51, 1994

[7] André P., Partition Functions and Concentrations in Plasmas out of Thermal Equilibrium, IEEE Transactions on Plasma Science, Vol 23, no3, 1995, pp453-458

[8] André P., Abbaoui M., Lefort A., Parizet M.J., Numerical Method and Composition in Multitemperature Plasma: Application to an Ar-H2 mixture, Plasma Chemistry and Plasma Processing, Vol 16, no3, 1996, pp379-398

[9] Aubreton J.; Elchinger M.F., Fauchais P., New Method to Calculate Thermodynamic and Transport Properties of a Multi-Temperature Plasma : Application to N2 Plasma, Plasma Chemistry and Plasma Processing, Vol 18, nol, 1998, pp1-27

[10] Fauchais P., Elchinger M.F., Aubreton J., Thermodynamic and Transport Properties of Thermal Plasmas, J. High.Temp. Material Processes, vol 4, no1, 2000, pp21-42

[11] Devoto R.S , The Transport Properties of a Partially Ionized Monoatomic Gas, Ph.D. Thesis (Standford University, 1965)

[12] Devoto R.S., Simplified Expressions for the Transport Properties of Ionized Monoatomic Gases, The Physics of Fluids, Vol 10, no10, 1967, pp2105-2112

[13] Bonnefoi C., Contribution à l'étude des méthodes de résolution de l'équation de Boltzmann dans un plasma à deux températures: exemple le mélange $\mathrm{Ar}-\mathrm{H}_{2}$, Thèse de Doctorat d'Etat (University of Limoges, France, 1983)

[14] Aubreton J., Bonnefoi C., Mexmain J.M., Calculation of thermodynamic and transport properties in an Ar- $\mathrm{O}_{2}$ atmospheric pressure plasma out of equilibrium (in French), Revue Phys. Appl., vol 21, 1986, pp365-376

[15] Rat V., Aubreton J., Elchinger M.F., Fauchais P., Plasma Chemistry and Plasma Processing, Calculation of combined diffusion coefficients from the simplified theory of transport properties, To be published

[16] André P., Aubreton J., Elchinger M.F., Rat V., Fauchais P., Lefort A., Theorem H in multi-temperature plasma, to be published. 